\title{
Definitions and engineering classifications of tropical lowland Peats
}

\author{
Mohamad Tarmizi Mohamad Zulkifley - Tham Fatt Ng • \\ John Kuna Raj • Roslan Hashim • Azman Ghani • \\ Mustaffa Kamal Shuib • Muhammad Aqeel Ashraf
}

Introduction

Peat classification methods for engineering purposes (such as peat-cement stabilization for ground improvement) and the main factors and aspects of these classification systems are discussed and reviewed, including such aspects as the organic content of peat and the degree of peat humification.

Definition of peat (general)

Understanding the formation of peat swamps requires an understanding of how organic deposits are formed and the conditions that lead to their development. Organic materials are formed by biochemical processes, whereas the process of organic material accumulation is mainly a direct function of environmental conditions, the climate, and the ecosystems (peat swamps, bogs or mires) in which the peat is formed. Organic materials only accumulate to form peat under certain conditions. It is essential that the production of biomass (organic materials) is greater than its chemical breakdown to form peat (Andriesse 1988).

Peats are generally considered to be partly decomposed biomass (vegetation). They exhibit a wide range of degrees of decomposition (Kurbatov 1968). Andriesse briefly summarizes the formation of peat as follows: "'The formation of 
peat is a relatively short biochemical process carried on under the influence of aerobic micro-organisms in the surface layers of the deposits during periods of low subsoil water (Andriesse 1974). As the peat which is formed in the peat-producing layer becomes subjected to anaerobic conditions in the deeper layers of the deposit, it is preserved and shows comparatively little change with time.' According to this theory, whether aerobic or anaerobic conditions are present determines whether biomass will accumulate and in what form. A distinction is made between forest peat, which is more aerated and therefore more decomposed, and peats formed under swampy conditions under strongly anaerobic conditions. In forest peat, lignin and carbohydrates appear to be completely decomposed, so forest peat generally has low contents of these organic compounds, whereas under swamp conditions, peats are characterized by high contents of cutin and the presence of a considerable amount of unaltered lignin and cellulose (Table 1) (Andriesse 1988; Kurbatov 1968).

Anaerobic swampy conditions, which prevent the microbiological activity needed for the chemical breakdown of organic materials, are generally assumed to be largely responsible for the accumulation of partly decomposed biomass/organic matter in the form of peat. Anaerobic conditions are created by a specific hydrotopography, be it marsh, swamp, bog, or mire. The properties of such hydrotopographic units depend on many environmental factors, including climate, landform, local geology, and hydrology (Andriesse 1974).

The definition of peat also implies the net accumulation of $100 \%$ pure organic matter, and the difference between soil and organic or vegetative accumulation varies (Murtedza et al. 2002; Andriesse 1974), most likely due to varying definitions in the different academic fields associated with the practical study of peat and its properties (agriculture, botany, geology, and engineering, for 
instance). "Peat"' has been described as "organic soil"' and as a histosol. Peat is described as organic soil on the basis of mass composition (Murtedza et al. 2002), i.e., soils that contain at least $65 \%$ organic matter or, conversely, less than $35 \%$ mineral content. The Soil Division of Sarawak (Malaysia) has adopted a definition for organic soil that is based on a profile partition, i.e., a soil that has $50 \mathrm{~cm}$ or more organic soil matter within a profile of $100 \mathrm{~cm}$ or a soil that has an organic matter content more than twice that of its mineral content overlying bedrock within $50 \mathrm{~cm}$ (Kurbatov 1968; Teng 1996).

The United States Department of Agriculture (USDA) defines soils as organic (or histosols) if more than half of the upper $80 \mathrm{~cm}$ of the soil is organic or if organic soil material of any thickness rests on rock or on fragmented material having interstices filled with organic materials (Murtedza et al. 2002).

Peats, as we now know, are formed by limited decomposition and hence the accumulation of organic soil materials, which can consist of undecomposed, partially decomposed, and highly decomposed plant remains. Tropical lowland peats usually contain undecomposed and partly decomposed branches, logs, and twigs (Fig. 1).

Tropical lowland peat forms a fragile ecosystem because of its domed shape and because it is almost purely organic (Muttalib et al. 1991; Paramananthan 1998). Tropical lowland soils have an isohyperthermic or warmer soil temperature regime (with a mean annual soil temperature of more than 22 _C and a monthly variation of less than $5 \_$C) and a common elevation of less than $750 \mathrm{~m}$ or $2,500 \mathrm{ft}$ above sea level (Paramananthan 1998). According to Paramananthan, lowland organic soils are soils in which the thickness of organic soil layers makes up more than half the soil to a depth of $100 \mathrm{~cm}$, or less if rocks or parent materials are present at less than $100 \mathrm{~cm}$ (Paramananthan 1998). 
Full text available at :

http://download.springer.com/static/pdf/616/art\%253A10.1007\%252Fs10064-013-0520-

5.pdf?auth $66=1387434665034 c 3$ ea4784d8f4e11b0fd795049foff\&ext=.pdf

http://link.springer.com/article/10.1007/s10064-013-0520-5 